\title{
Determination of Thallium Traces by ETAAS after On-Line Matrix Separation and Preconcentration in a Flow Injection System
}

\author{
Taherah Asadoulahi, Shayessteh Dadfarnia* and Ali Mohammad Haji Shabani
}

\author{
Department of Chemistry, Faculty of Sciences, Yazd University, Yazd, 89195-741, Iran
}

\begin{abstract}
Um sistema de injeção em fluxo sensível e simples foi desenvolvido para separação, préconcentração e determinação de tálio. A pré-concentração é baseada na sorção do analito em uma microcoluna de dibenzo-18-coroa-6 (DB18C6) imobilizada em alumina revestida com surfactante e subseqüente eluição com solução de ácido nítrico $\left(500 \mu \mathrm{L}, 2 \mathrm{~mol} \mathrm{~L}^{-1}\right)$. A concentração de tálio no eluente foi determinada por espectrometria de absorção atômica com atomização eletrotérmica. Os fatores que influenciaram a sorção e dessorção de íon tálio foram investigados. Para um volume da amostra de $5 \mathrm{~mL}$, a calibração foi linear no intervalo de 0,1 a $20 \mu \mathrm{g} \mathrm{L}^{-1}(\mathrm{r}=$ $0,9996)$ com um limite de detecção de $0,05 \mu \mathrm{g} \mathrm{L}^{-1}$. A capacidade máxima de sorção foi de 1432 $\mu \mathrm{g}$ de tálio por grama do sorbente. A precisão do método para $1 \mu \mathrm{g} \mathrm{L}^{-1}$ foi $5,7 \% \operatorname{RSD}(\mathrm{n}=11)$. O método foi aplicado para determinação de tálio em água, cabelo, unha e em materiais de referência certificados. A exatidão foi avaliada empregando experimentos de adição e recuperação ou por comparação dos resultados com materiais de referência certificados.
\end{abstract}

A simple and sensitive flow injection system was developed for separation, preconcentration and determination of thallium. Preconcentration is based on the analyte sorption on a microcolumn of dibenzo-18-crown-6 (DB18C6) immobilized on surfactant coated alumina with subsequent elution using a nitric acid solution $\left(500 \mu \mathrm{L}, 2 \mathrm{~mol} \mathrm{~L}^{-1}\right)$. The concentration of thallium in the eluent was determined using electrothermal atomic absorption spectrometry. Factors influencing the sorption and desorption of thallium ion were investigated. Using a sample volume of $5 \mathrm{~mL}$, the calibration was linear from 0.1 to $20 \mu \mathrm{g} \mathrm{L}^{-1}$ range $(\mathrm{r}=0.9996)$ with a detection limit of $0.05 \mu \mathrm{g} \mathrm{L}^{-1}$. The maximum sorption capacity was $1432 \mu \mathrm{g}$ of thallium per gram of sorbent. The precision of the method at $1 \mu \mathrm{g} \mathrm{L} \mathrm{L}^{-1}$ was $5.7 \% \mathrm{RSD}(\mathrm{n}=11)$. The method was applied for determination of thallium in water, hair, nail, and standard reference samples. The accuracy was assessed using addition-recovery experiment or by comparison of the results with certified reference materials.

Keywords: thallium determination, immobilized crown ether, flow injection, electrothermal atomic absorption spectrometry, matrix separation, analyte preconcentration

\section{Introduction}

Thallium and its compounds are used in high tech industries such as semiconductors, low temperature thermometers, scintillation counter, nuclear medicine, dye and pigment. The main anthropogenic sources of thallium are emission from industrial processes, such as smelting of zinc and lead sulfide, and burning of coal and cement. Because of its toxicity, it was included in the list of 129 so-called "priority pollutants" by the US Environmental Protection Agency. ${ }^{1}$ It is regarded as one of the most toxic of the heavy metals, causing both chronic and acute

*e-mail: sdadfarnia@yazduni.ac.ir poisoning. ${ }^{1,2}$ Thus, thallium poisoning is recognized as an industrial hazard and its monitoring in different matrices have drawn the attention of researchers. ${ }^{3-6}$ The extremely low concentration of thallium in environmental sample (down to $n g \mathrm{~L}^{-1}$ level) requires an analytical method featuring high sensitivity and a low detection limit. Thallium had been determined by inductively coupled plasma mass spectrometry (ICP- MS) ${ }^{6-8}$ and laser-excited atomic fluorescence spectrometry (LEAFS). ${ }^{9}$ However, ICP-MS is an expensive analytical method and incurs high running cost, and LEAFS is less frequently used. ${ }^{9}$

Electrothermal atomic absorption spectrometry (ETAAS) appears to be the method of choice for determination of metal at very low concentration. ${ }^{10}$ This 
very sensitive and relatively simple method has been used by several workers for determination of thallium., ${ }^{4,11-14}$ However, direct determination of thallium with ETAAS involves many difficulties because of spectral and non spectral interference in environmental matrices. ${ }^{15}$ The absorbance signal of thallium is seriously depressed by the presence of chloride in the graphite furnace. This is due to the formation of volatile thallium monochloride with high dissociation energy in the condense phase which is difficult to dissociate in the gas phase. The presence of sulfate and iron, a common constituent of environmental samples, cause spectral interference, because the molecular absorption of $\mathrm{SO}_{2}$ has a maximum around the $\mathrm{Tl}$ line and exhibits a pronounced rotational fine structure. Also iron has an atomic band near the resonance line of thallium. Thus, a separation/preconcentration step is beneficial for determination of thallium in real sample.

Several separation/enrichment techniques, such as liquid-liquid extraction, ${ }^{11,16}$ flotation, ${ }^{17,18}$ separation on a chelex 100 resin column, ${ }^{18}$ and solid phase extraction using cellulose nitrate resin $(\mathrm{CNR})^{12}$ or polyurethane foam ${ }^{20}$ have been used for determination of thallium with ETAAS. However, these manual batch procedures are labor, time and reagent consuming, and require large volume of samples.

Flow injection (FI) separation and preconcentration techniques are effective for enhancing sensitivity of atomic spectrometry which provides a simple and rapid procedure for Tl determination. However, automation of determination of thallium with ETAAS is just beginning..$^{21,22}$ Ivanova et al. ${ }^{21}$ reported a flow injection on-line sorption preconcentration in a knotted reactor coupled with ETAAS for determination of thallium. $\mathrm{Tl}^{3+}$-tetramethylenedithiocarbamate (pyrrolidinedithiocarbamate) complex was sorbed on the inner walls of a PTFE knotted reactor and eluted with $45 \mathrm{~mL}$ of ethanol. The adsorption efficiency of $51 \%$ and detection limit of $0.015 \mathrm{mg} \mathrm{L}^{-1}$ was reported. Also, $\mathrm{Xu}$ et al..$^{22}$ developed a sequential injection system for on-line sorbent extraction preconcentration in ETAAS for determination of traces of thallium in geochemical samples. The $\mathrm{TlBr}_{4}^{-}$complex was adsorbed on a packed microcolumn of XAD-8 resin and was eluted by injection of $50 \mu \mathrm{L}$ of acetone. An enrichment factor of 15 and detection limit of $18 \mathrm{ng} \mathrm{L}^{-1}$ was reported. Thus, development and application of FIA-ETAAS for performing pretreatment and measurement steps for determination of thallium is still attractive area of research.

Macrocyclic polyether commonly called crown ethers are ion-selective reagents that had been widely studied within separation science. ${ }^{23-26}$ The commercially available immobilized crown ether ( $\mathrm{Pb}-\mathrm{Spec}$ and $\mathrm{Sr}-\mathrm{Spec}$ resin) has been used for preconcentration of lead in various matrices. ${ }^{27,28}$ The physical immobilization of crown ether on the knotted reactor has been also used for preconcentration and separation of palladium in tunnel dust. ${ }^{29}$ However, to the best of our knowledge, reports on physical immobilization of crown ethers on solid supports used as the sorbent for preparation of column or microcolumn of solid phase extraction of metal ions is rare..$^{30}$

Over the past decade, the effectiveness and versatility of physically immobilization of chelating agents on surfactant coated alumina as a column preconcentration media in batch $^{31-33}$ and FIA ${ }^{34-36}$ system had been demonstrated. However, hitherto no such study has been directed for immobilization of macrocyclic ligands. So, it was appropriate to investigate the possibility of physical immobilization of crown ether. Recent studies have confirmed the immobilization of dibenzo-18-crown-6 (DB18C6) on surfactant coated alumina. Also, a rapid method has been developed for matrix separation and preconcentration of thallium in different sample on FI-ETAAS.

\section{Experimental}

\section{Reagents}

All chemicals and solvents were analytical reagent grade, which were used without further purification. The chemicals were purchased from Merck Company, Germany, unless otherwise stated. Double deionized water was used throughout. A stock solution $\left(100 \mathrm{mg} \mathrm{L}^{-1}\right)$ of $\mathrm{Tl}^{+}$ and $\mathrm{Tl}^{3+}$ was prepared by dissolving an accurate mass of either $\mathrm{TlNO}_{3}$ or $\mathrm{Tl}\left(\mathrm{NO}_{3}\right)_{3} \cdot 3 \mathrm{H}_{2} \mathrm{O}$ into a $100 \mathrm{~mL}$ flask and diluting to the mark with distilled water. Standard solutions were prepared daily from the stock solution by serial dilution with water. $\mathrm{Pd} / \mathrm{Mg}$ modifier was prepared from palladium modifier solution for ETAAS and $\mathrm{Mg}$ $\left(\mathrm{NO}_{3}\right)_{2} \cdot 6 \mathrm{H}_{2} \mathrm{O}$ according to reference..$^{37,38}$

Alumina $(10-50 \mu \mathrm{m}, \gamma$-type chromatography grade) was purified by shaking with $5 \mathrm{~mol} \mathrm{~L}^{-1}$ nitric acid and washing three times with water. Sodium dodecyl sulfate (SDS), dibenzo-18-crown-6 (DB18C6) (Fluka) and 18crown-6 (18C6) (Fluka) were used without further purification. A $0.1 \%$ solution of DB18C6 was prepared by dissolving $100 \mathrm{mg}$ of DB18C6 in acetone. Reagent blank was prepared by processing a solution of $2 \mathrm{~mol} \mathrm{~L}^{-1}$ nitric acid through a column of immobilized DB18C6.

\section{Apparatus}

Varian Zeeman spectra atomic absorption spectrometer, Model $220 \mathrm{Z}$ with an auto sampler was used 
in this study. Recording of the absorbance signal profile was done with a PC computer. A Varian spectra-AA hollow cathode lamp for thallium was also used as the light source. The furnace tube was a standard platform tube with a pyrolytic graphite coating. The analytical wavelength $(276.8 \mathrm{~nm})$, spectral bandwidth $(0.5 \mathrm{~nm})$, lamp current $(10 \mathrm{~mA})$ and the furnace programme (Table 1) were used as recommended by the manufacturers. Peak height measurement was used for all quantifications. The flow injection manifold consisted of peristaltic pump (Ismatec, Ms-4 REGLO 8-100, Switzerland), rotary injection valve (Rheodyne, California, USA) and microcolumn of dibenzo-18-crown-6 immobilized on surfactant-coated alumina (PTFE, tube $3 \mathrm{~cm} \times 2 \mathrm{~mm}$ i.d.)

Table 1. Temperature program of ETAAS

\begin{tabular}{lccc}
\hline Steps & $\mathrm{T} /{ }^{\circ} \mathrm{C}$ & time $/ \mathrm{s}$ & $\begin{array}{c}\text { Argon flow } \\
\text { rate } /\left(\mathrm{L} \mathrm{min}{ }^{-1}\right)\end{array}$ \\
\hline Drying & 85 & 5.0 & 3.0 \\
Drying & 95 & 40.0 & 3.0 \\
Drying & 120 & 10.0 & 3.0 \\
Pyrolysis & 250 & 5.0 & 3.0 \\
Pyrolysis & 250 & 1.0 & 3.0 \\
gas stop & 250 & 2.0 & 0.0 \\
atomization \& & 2200 & 1.0 & 0.0 \\
read command & & & \\
atomization \& & 2200 & 2.0 & 0.0 \\
read command & & & \\
tube cleaning & 2200 & 2.0 & 3.0 \\
\hline
\end{tabular}

\section{Preparation of the sorbent and microcolumn}

A volume of $50 \mathrm{~mL}$ of a solution $(\mathrm{pH} \approx 2)$ containing $100 \mathrm{mg}$ SDS and $1.5 \mathrm{~g}$ of alumina was mixed with a magnetic stirrer for $10 \mathrm{~min}$. The supernatant was decanted and the SDS-coated alumina was washed thoroughly with water. Then $c a .20 \mathrm{~mL}$ of water and 5-7 $\mathrm{mL}$ of crown ether $(0.1 \mathrm{~g}$ dissolved in acetone) was added. The solution was shaken for $15 \mathrm{~min}$. The mixture was then filtered through a Millipore filter, washed, air-dried and kept in a closed bottle before use. It was stable for over 4 months. The resulting sorbent was characterized by employing Fourier transform infrared spectrometry (FTIR). The characteristic IR bands in $\mathrm{cm}^{-1}$ for immobilized DB18C6 were: $1454.5,1509.7$, and 1596.4 (skeleton bands of aromatic rings) and 1131.0, 1231.1, 1255.9, and 1331.0 (C-O stretching). These prove the loading of crown ether on SDS coated alumina.

A microcolumn was fabricated by using PTFE (Teflon) tubing $(3 \mathrm{~cm}$ in length with internal diameter of $2 \mathrm{~mm}$ ) containing DB18C6 immobilized on surfactant coated alumina ( $c a .60 \mathrm{mg}$ ). The end of the tube was fitted with foam to retain the sorbent in the tube.
Preparation of real samples

\section{Hair and nail}

The hair and nail sample were rinsed with acetone, chloroform and doubly deionized distilled water, and finally dried at $60{ }^{\circ} \mathrm{C}$. Exact amount of dried sample ( $0.1194 \mathrm{~g}$ for nail or $1 \mathrm{~g}$ for hair) was placed in three 50 $\mathrm{mL}$ beakers and $5 \mathrm{~mL}$ concentrated $\mathrm{HNO}_{3}$ was added to the beakers. The beakers were then heated on a hot plate (initially at $100{ }^{\circ} \mathrm{C}$ for $45 \mathrm{~min}$ and then at $120^{\circ} \mathrm{C}$ for 15 $\mathrm{min})$. Following dissolution, the solution was cooled to $70{ }^{\circ} \mathrm{C}$ and $2 \mathrm{~mL}$ of $30 \% \mathrm{~m} / \mathrm{m} \mathrm{H}_{2} \mathrm{O}_{2}$ was added. The mixtures were heated to dryness on a hot plate, with the temperature set at $150{ }^{\circ} \mathrm{C}$, to yield a white residue. Approximately $10 \mathrm{~mL}$ of $0.1 \mathrm{~mol} \mathrm{~L}^{-1} \mathrm{HNO}_{3}$ was added to the beakers and the contents were heated at $100{ }^{\circ} \mathrm{C}$ for 1 $\mathrm{h}$. The $\mathrm{pH}$ of solutions was adjusted to $c a$. 8. The solutions were then transferred to a $50 \mathrm{~mL}$ volumetric flask and the volumes were adjusted upon addition of distilled water.

\section{Water and urine}

The samples were filtered through a Millipore filter; the $\mathrm{pH}$ was adjusted to $c a .8$ with ammonium hydroxide solution, and was treated according to the given procedure.

\section{Certified reference materials}

A volume of $5 \mathrm{~mL}$ of concentrated nitric acid was added to $0.1 \mathrm{~g}$ of ore sample (BCR, No. 288 certified reference material). The solution was heated over a water bath for few minutes and $2 \mathrm{~mL}$ of $30 \% \mathrm{~m} / \mathrm{m} \mathrm{H}_{2} \mathrm{O}_{2}$ was added. The solution was filtered, diluted with water and the $\mathrm{pH}$ was adjusted to $c a$. 8 . The solution was then transferred to 50 $\mathrm{mL}$ flask, and was diluted with addition of distilled water.

Also $2 \mathrm{~mL}$ of concentrated nitric acid was added to $0.1403 \mathrm{~g}$ of igneous rocks (GSJ reference sample). The solution was heated over a water bath for $c a .45 \mathrm{~min}$, and few drops of $\mathrm{H}_{2} \mathrm{O}_{2}$ were added. The solution was then heated to nearly dryness. Few $\mathrm{mL}$ of water was added to the solution, filtered, and $\mathrm{pH}$ was adjusted. The mixture was diluted to $20 \mathrm{~mL}$ and was treated according to the given procedure.

\section{Recommended procedure}

The flow injection manifold is presented in Figure 1. The microcolumn of immobilized DB18C6 on surfactant coated alumina was used as the operation column and was located in the sample loop of injection valve. At the end of sampling (Figure 1a), the valve 1 was switched on-line and water ( $c a .1 \mathrm{~min})$ and air was passed through the microcolumn respectively (Figure 1b). Then the eluent 
(500 $\mu \mathrm{L}, 2 \mathrm{~mol} \mathrm{~L}^{-1}$ ) was injected with the use of second valve to promote elution (Figure 1c).

a)

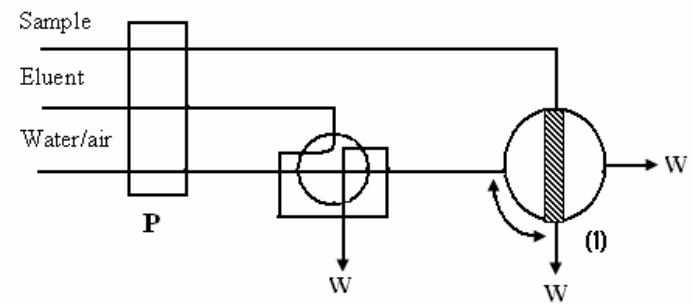

b)
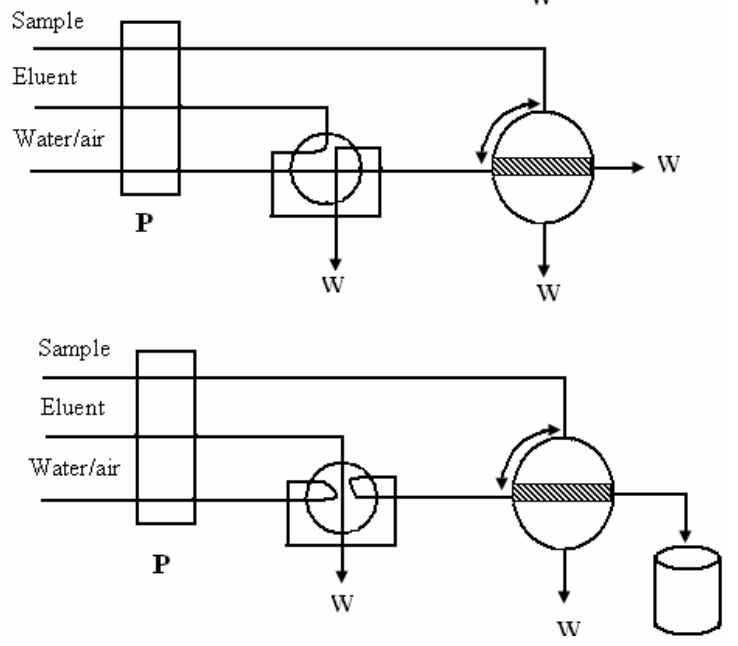

Figure 1. Schematic of flow injection manifold; a) preconcentration step; b) washing/drying step; c) elution step; P: peristaltic pump; W: waste; flow rate $3 \mathrm{~mL} \mathrm{~min}^{-1}$, eluent ( $500 \mu \mathrm{L}, 2 \mathrm{~mol} \mathrm{~L}^{-1} \mathrm{HNO}_{3}$ ), and sample $\mathrm{pH} \sim 8$.

The $\mathrm{pH}$ of solution was adjusted to $c a .8$ with ammonium hydroxide solution. Standard solution or samples were passed through the immobilized crown ether microcolumn (time based sampling e.g. 2 min at a flow rate of $3 \mathrm{~mL} \mathrm{~min}-1$ ) to promote the sorption of the analyte (Figure 1a). The column was washed then with water to remove all traces of the sample matrix. Then, air was drawn into the microcolumn in order to completely evacuate it between sample loading and elution, so that excess liquid will not end up in the graphite tube in the final elution step (Figure 1b). The retained analyte was then eluted by injection of nitric acid $\left(500 \mu \mathrm{L}, 2 \mathrm{~mol} \mathrm{~L}^{-1}\right)$ and the eluent was directly collected into an auto sampler cup of the graphite furnace (Figure 1c). Afterwards, thallium was determined by ETAAS. The column was re-established by processing ca. $2 \mathrm{~mL}$ of water through the column before the next sorption/elution cycle.

\section{Results and Discussion}

Preliminary experiment had shown that when DB18C6 or 18C6 is added to the solution containing particle of alumina coated with SDS, the crown ethers trapped homogenously on the hemi micelles or ad-micelles formed by SDS on the alumina surface in a manner similar to reports for classical ligands. ${ }^{31-36}$ It was also confirmed that, while microcolumn of alumina or alumina coated with SDS show no tendency for retention of thallium ions, the microcolumn of immobilized macrocycle on surfactant coated alumina was capable of retaining thallium ions from the sample solution quantitatively. However, the immobilized DB18C6 sorbent was more stable with better repeatability than immobilized $18 \mathrm{C} 6$ at high preconcentration volume. Therefore, it was chosen as the sorbent for subsequent work. Furthermore, the effect of modifier on determination of thallium was considered. Different recommended modifiers ${ }^{38-40}$ such as palladium, sulfuric acid, ascorbic acid and palladium/ magnesium were also examined. It was found that $\mathrm{Pd} / \mathrm{Mg}$ were the most suitable modifier for this purpose, which is consistent with the previous report. ${ }^{38}$ With ascorbic acid, $\mathrm{Pd}$, and $\mathrm{H}_{2} \mathrm{SO}_{4}$, the background absorption was high with wide peak, and the linearity of calibration graph was limited.

In order to achieve the best performance from this system, different parameters were optimized. The $\mathrm{pH}$ of sample solution, effect of sample and eluent flow rate on the extraction efficiency, nature and concentration of eluent, amount of sorbent, and the effect of sample volume along with maximum capacity of the sorbent for thallium $\left(\mathrm{Tl}^{+}\right)$recovery were studied. The procedure was optimized by using the univariate method.

\section{Effect of sample $\mathrm{pH}$ and mass of packing material}

The effect of sample $\mathrm{pH}$ on the retention of thallium $\left(25 \mathrm{ng}\right.$ of $\mathrm{Tl}^{+}$) was studied by varying the $\mathrm{pH}$ within the range of 1-11. The $\mathrm{pH}$ was adjusted by using $0.1 \mathrm{~mol} \mathrm{~L}^{-1}$ of either nitric acid or ammonium hydroxide solution. The results showed (Figure 2) that the absorbance was increased with $\mathrm{pH}$ increase up to 6 , and then leveled off at higher $\mathrm{pH}$. The progressive decrease in absorbance at lower $\mathrm{pH}$ is due to competition of proton with $\mathrm{Tl}^{+}$for complexation with DB18C6 $\left(\log \mathrm{K}_{\mathrm{f}}\left(\mathrm{Tl}^{+} / \mathrm{DB} 18 \mathrm{C} 6\right)=5.05\right.$, and $\log \mathrm{K}_{\mathrm{f}}\left(\mathrm{H}^{+} /\right.$ DB18C6) $=2.3) .{ }^{41}$ An optimum $\mathrm{pH}$ of 8 was selected for subsequent experiments. The effect of length of column on efficiency of analyte sorption was considered and a packed column with a length of $3 \mathrm{~cm}$ (corresponding to a $c a$. 60 $\mathrm{mg}$ of sorbent) was found to be sufficient.

\section{Effect of sample flow rate on analyte sorption}

The flow rate of the sample establishes the contact time between the sample solution and the sorbent. The effect of 
sample flow rate on analyte sorption was considered by varying the flow rate from 1-6 $\mathrm{mL} \mathrm{min}^{-1}$, while keeping the amount of preconcentration analyte constant $(25 \mathrm{ng}$ of $\mathrm{Tl}^{+}$). It was found that the kinetic of adsorption is fast and independent of the flow rate. Flow rate greater than 6 $\mathrm{mL} \min ^{-1}$ was not tested because of the increasing back pressure in the system. In order to achieve a good precision, a flow rate of $3 \mathrm{~mL} \mathrm{~min}^{-1}$ was chosen for subsequent studies.

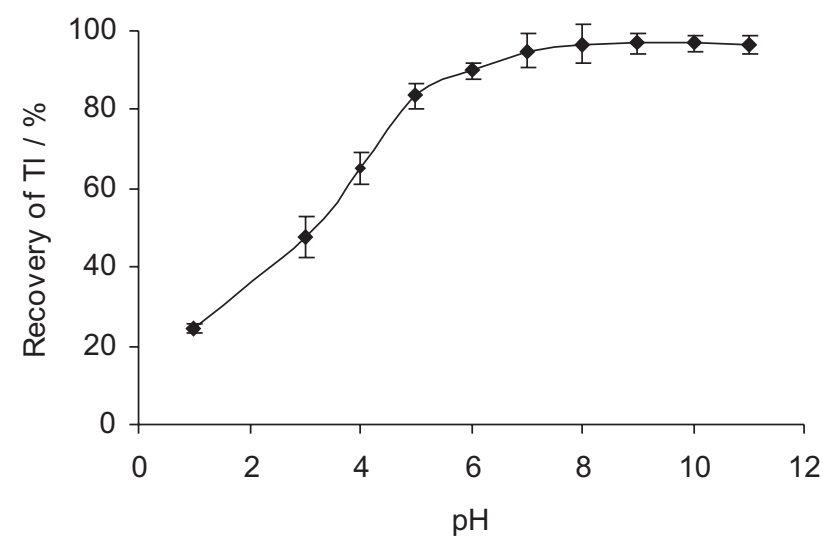

Figure 2. Effect of $\mathrm{pH}$ on thallium retention, $\mathrm{Tl}^{+}$solution $(5 \mathrm{~mL}, 5 \mu \mathrm{g}$ $\left.\mathrm{L}^{-1}\right)$ and eluent $\left(500 \mu \mathrm{L}, 2 \mathrm{~mol} \mathrm{~L}^{-1} \mathrm{HNO}_{3}\right)$.

\section{Selection of desorpting solution}

In order to find the best eluent for desorbing the thallium ion from the sorbent, a series of eluents such as sulfuric, phosphoric, acetic and nitric acid at concentration level of 2 mol L-1 were selected. $5 \mathrm{~mL}$ of solution containing $25 \mathrm{ng}$ of thallium was passed through the sorbent at a flow rate of 3 $\mathrm{mL} \mathrm{min}{ }^{-1}$. The adsorbed thallium was then eluted by passing $500 \mu \mathrm{L}$ of the aforementioned eluent, and the amount of thallium was determined by ETAAS. The results showed that the best recovery and peak shape was achieved with nitric acid. The background absorbance was high with $\mathrm{H}_{2} \mathrm{SO}_{4}$, due to formation of molecular $\mathrm{SO}_{2}$; while with $\mathrm{H}_{3} \mathrm{PO}_{4}$, the absorbance peak split in two parts, and the recovery was low with acetic acid.

\section{Effect of concentration, volume and flow rate of eluent on desorption of analyte}

The effect of concentration of nitric acid on the recovery of thallium ion was studied. For desorbing $25 \mathrm{ng}$ of thallium ions retained on microcolumn, different concentration of eluents were used. The results indicate that quantitative recovery ( $>95 \%$ ) for thallium ion was achieved at $1.5 \mathrm{~mol}$ $\mathrm{L}^{-1}$ of nitric acid and then leveled off at higher concentration. Therefore, for subsequent work, $500 \mu \mathrm{L}$ nitric acid with a concentration of $2 \mathrm{~mol} \mathrm{~L}^{-1}$ was chosen as eluent. The effect of varying the eluent flow rate (fixed flow rate for sorption) was considered by varying the flow rate from $1-7 \mathrm{~mL} \mathrm{~min}^{-1}$. It was found that the kinetic of desorption is fast and independent of the flow rate. Flow rate above $7 \mathrm{~mL} \mathrm{~min}^{-1}$ was not tested due to the back pressure in the system. For convenience, a flow rate of $3 \mathrm{~mL} \mathrm{~min}{ }^{-1}$ was selected. Furthermore, the effect of eluent volume on recovery was examined by using three loops with the sizes of 250,500 , and $750 \mu \mathrm{L}$. It was found that $500 \mu \mathrm{L}$ of eluent was sufficient for quantitative recovery of thallium.

\section{Evaluation of sorbent properties}

The capacity of immobilized DB18C6 sorbent was examined by processing different volumes $(5-20 \mathrm{~mL})$ of thallium solution $\left(20 \mathrm{mg} \mathrm{L}^{-1}\right)$ at optimum condition through the microcolumn containing $60 \mathrm{mg}$ of sorbent. The retained analyte was then eluted with $500 \mu \mathrm{L}$ of 2 mol L-1 nitric acid, collected in $10 \mathrm{~mL}$ volumetric flask, and diluted to the mark with distilled water. The thallium content was determined by FAAS. The breakthrough capacity of the microcolumn under the working conditions was found to exceed $1432 \mu \mathrm{g}$ of thallium per gram of packing material. Furthermore, the capacity of the sorbent for retention of thallium was examined in the batch experiments and was found to be $1693 \pm 4 \mu \mathrm{g} \mathrm{g}^{-1}$ of packing material. The results were in agreement with the finding of FI experiment. This high value indicated the high performance of the microcolumn for thallium enrichment, even in the presence of competing ions.

The capability of microcolumn for preconcentration of $\mathrm{Tl}^{+}$and $\mathrm{Tl}^{3+}$ was considered by processing $5 \mathrm{~mL}$ of 10 $\mu \mathrm{g} \mathrm{L}^{-1}$ solution of either $\mathrm{Tl}^{+}, \mathrm{Tl}^{3+}$ or mixture of both according to the given procedure. The results also revealed that the column did not distinguish between different species of thallium; thus, the microclumn is capable of retaining both $\mathrm{Tl}^{+}$and $\mathrm{Tl}^{3+}$ ions.

A single microcolumn was subjected to seven loadings with sample solution and subsequent elution with eluent. It was observed that retention properties of the sorbent did not change, even after seven cycles of sorption and desorption. Furthermore, by processing hundreds of sample retention and elution cycles during the course of this work, the stability of newly synthesized sorbent was tested, which was stable over for 4 months.

\section{Interference study}

The sensitivity and utility of the microcolumn in the preconcentration of thallium in the presence of potential interfering ions in water and environmental samples at a initial mole ratio of 1000 (ion/thallium) was examined, 
however, when an interference was observed the concentration of interfering ion was lowered (Table 2). A relative error of less than $10 \%$ was considered to be within the range of experimental error. At the given level, no significant interference was observed in the determination of thallium at trace levels. Thus, the present system indicates that high concentration of matrix salts, have minimal effect on thallium species relative to matrix ions.

Table 2. Interference study

\begin{tabular}{lcrccr}
\hline $\begin{array}{l}\text { Coexisting } \\
\text { ions }\end{array}$ & $\begin{array}{c}\text { Mol } \\
\text { ratio }\end{array}$ & Recovery/\% & $\begin{array}{c}\text { Coexisting } \\
\text { ions }\end{array}$ & $\begin{array}{l}\text { Mol } \\
\text { ratio }\end{array}$ & Recovery/\% \\
\hline $\mathrm{Mg}^{2+}$ & $1000^{*}$ & $100.1 \pm 5.0$ & $\mathrm{Cd}^{2+}$ & 500 & $98.2 \pm 3.0$ \\
$\mathrm{Na}^{+}$ & $1000^{*}$ & $95.4 \pm 6.1$ & $\mathrm{Ag}^{+}$ & 750 & $99.1 \pm 1.3$ \\
$\mathrm{Ca}^{2+}$ & $1000^{*}$ & $96.2 \pm 4.2$ & $\mathrm{Cs}^{+}$ & 250 & $94.0 \pm 4.1$ \\
$\mathrm{~K}^{+}$ & 250 & $94.5 \pm 5.1$ & $\mathrm{Fe}^{2+}$ & 500 & $93.5 \pm 3.4$ \\
$\mathrm{Zn}^{2+}$ & 500 & $105.1 \pm 2.2$ & $\mathrm{Cl}^{-}$ & 500 & $95.2 \pm 2.2$ \\
$\mathrm{~Pb}^{2+}$ & 500 & $94.1 \pm 3.2$ & $\mathrm{CO}_{3}^{2-}$ & 500 & $104.1 \pm 1.1$ \\
$\mathrm{Cu}^{2+}$ & 500 & $95.2 \pm 2.4$ & $\mathrm{I}^{-}$ & 750 & $105.0 \pm 2.3$ \\
$\mathrm{C}^{2+}$ & 750 & $94.5 \pm 4.1$ & $\mathrm{PO}_{4}^{3-}$ & 250 & $94.5 \pm 3.2$ \\
$\mathrm{Ni}^{2+}$ & 750 & $103.0 \pm 2.0$ & & & \\
\hline
\end{tabular}

*maximum value tested.

\section{Analytical figures of merit}

Analytical figures of merit were evaluated for the proposed system using $5 \mathrm{~mL}$ aliquot of thallium solution (0.1-20 $\left.\mu \mathrm{g} \mathrm{L}^{-1}\right)$, which after sorption on the sorbent was eluted with $500 \mu \mathrm{L}$ of $2 \mathrm{~mol} \mathrm{~L}^{-1}$ nitric acid. The calibration curve obtained upon analysis of the eluent using ETAAS had the equation $\mathrm{A}=0.0243 \mathrm{C}+0.0027$ with $\mathrm{r}^{2}=0.9993$, where $\mathrm{A}$ is the absorbance value of the eluent, and $\mathrm{C}$ is the concentration of thallium $\left(\mu \mathrm{g} \mathrm{L}^{-1}\right)$ in solution. With 5 $\mathrm{mL}$ sampling volume over 30 samples were concentrated in $1 \mathrm{~h}$; however, analysis using ETAAS took longer time (Table 1). The precision of the method for eleven replicate measurements for standard solution $(5 \mathrm{~mL})$ containing 1 $\mu \mathrm{g} \mathrm{L}^{-1}$ of thallium was $5.7 \%$ expressed as relative standard deviation.

The limit of detection (LOD), defined as the concentration of thallium that gives a response equivalent to three times the standard deviation of the blank analyses (3S) for processing $5 \mathrm{~mL}$ volume were $0.05 \mu \mathrm{g} \mathrm{L}^{-1}$.

\section{Analysis of real sample}

In order to assess the applicability of the method to real sample, the procedure was applied to the determination of thallium in water (tap, well and spring water), hair and nail samples. The reliability was checked using spikes (Table 3). It was shown that the recovery of spiked sample was good, suggesting that the proposed method is suitable for preconcentraion of thallium ion at the trace level in the sample type examined. The procedure was also applied for determination of thallium in two different certified reference materials, namely, BCR No 288 and igneous rock (GSJ), with thallium concentration of $2.3 \pm 0.1$ and $1.54 \mu \mathrm{g} \mathrm{g}^{-1}$, respectively. The accuracy of the method was checked by comparing the data with the certified value. The amount of thallium in BCR and igneous rock were found to be $2.35 \pm 0.15$ and $1.58 \pm 0.12 \mu \mathrm{g} \mathrm{g}^{-1}$ respectively. This indicates that at $95 \%$ confidence limit there is no significant difference between these results and certified values, which confirm the suitability of the method for this type of sample. Thus, the procedure is reliable for determination of thallium in a wide range of samples.

Table 3. Analysis of real sample

\begin{tabular}{|c|c|c|c|}
\hline Sample & $\begin{array}{c}\text { Amount }^{\mathrm{b}} \\
\text { added }\end{array}$ & $\begin{array}{l}\text { Amount } \\
\text { found }^{\mathrm{a}, \mathrm{b}}\end{array}$ & Recovery / \% \\
\hline \multirow[t]{2}{*}{ Tap water } & - & $<0.05$ & 100.0 \\
\hline & 5 & $5.01 \pm 0.31$ & \\
\hline \multirow[t]{2}{*}{ Well water } & - & $1.01 \pm 0.10$ & 99.4 \\
\hline & 5 & $5.97 \pm 0.30$ & \\
\hline \multirow[t]{2}{*}{ Spring water } & - & $1.80 \pm 0.05$ & 95.8 \\
\hline & 5 & $6.59 \pm 0.41$ & \\
\hline \multirow[t]{2}{*}{ Nail } & - & $0.50 \pm 0.03$ & 105.0 \\
\hline & 0.21 & $0.72 \pm 0.04$ & \\
\hline \multirow[t]{2}{*}{ Hair } & - & $0.16 \pm 0.01$ & 96.0 \\
\hline & 0.25 & $0.40 \pm 0.02$ & \\
\hline
\end{tabular}

${ }^{a}$ average and standard deviation of three replicate determination; ${ }^{\mathrm{b}} \mu \mathrm{g} \mathrm{L} \mathrm{L}^{-1}$ and $\mu \mathrm{g} \mathrm{g}^{-1}$ for liquid and solid sample respectively.

\section{Conclusions}

This study presents a simple method for physical immobilization of crown ether ligands such as DB18C6 on solid support used for preparation of column and microcolumn for extraction of ions. Furthermore, the proposed FI system incorporating immobilized DB18C6 microcolumn permits effective separation and preconcentration of thallium and final determination by ETAAS in different matrices.

The main benefits of this system were the easy preparation of the sorbent, high stability and repeatability of the microcolumns, high tolerance to interference from the matrix ions in different samples, enhanced sensitivity of ETAAS, and low cost. Future work will address the suitability of the immobilized microcolumn for field sampling of thallium.

\section{References}

1. Townshend, A; Encyclopedia of Analytical Science, Academic Press: London 1995. 
2. Asami, T.; Mizuic, C.; Shimada, T.; Kubota, M.; Fresenius J. Anal. Chem. 1996, 356, 348.

3. Das, A. K.; Chakraborty, R.; Cervera. M. L., de la Guardia, M. D. I.; Anal. Bioanal. Chem. 2006, 385, 665.

4. Nukatsuka, I.; Seitoh, H.; Ohzeki, K.; Microchim. Acta 2004, $148,177$.

5. Twining, B. S.; Twiss, M. R.; Fisher, N. S.; Environ Sci. Technol. 2003, 137, 2720.

6. Karthikeyan, J.; Parameshwara, P.; Shetty, A. N.; Shetty P.; J. Braz. Chem. Soc. 2006, 17, 316.

7. Saleh, M. A.; Ewane, E.; Jones, J.; Wilson, B. L.; J. Food Compos. Anal. 2001, 14, 127.

8. Dabeka, R. W.; Conacher, H. B. S.; Lawrence, J. F.; Newsome, W. H.; Mckenzie, A.; Wagner, H. P.; Chadha, R. K. H.; Pepper, K.; Food Addit. Contam. 2002, 19, 721.

9. Cheam, V.; Lawson, G.; Lechner, J.; Desrosiers, R.; Nriagu, J.; Fresenius J. Anal. Chem. 1996, 355, 332.

10. Fernandes, K. G.; Nogueira, A. R. A.; Gomes Neto, J. A.; Nóbrega, J. A.; J. Braz. Chem. Soc. 2004, 15, 676.

11. Zendelovska, D.; Stafilov, T.; Anal. Sci. 2001, 17, 425.

12. Nukatsuka, I.; Horiguchi, R.; Seitoh, H.; Ohzeki, K.; Miyashita, F.; J. AOAC Int. 2004, 87, 986.

13. Villar, M.; Alava, F.; Lavilla, I.; Bendicho, C.; J. Anal. At. Spectrom. 2004, 16, 1424.

14. Silva, A. F.; Borges, D. L. G.; Welz, B.; Vale, M. G. R.; Silva, M. M.; Klassen, A.; Heitmann, U.; Spectrochim. Acta, Part B 2004, 59, 841 .

15. Goreti, M.; Vale, R.; Welz, B.; Spectrochim. Acta, Part B 2002, $57,1821$.

16. Cvetkovic, J.; Arpadjan, S.; Karadjova, I.; Stafilov, T.; Spectrochim. Acta, Part B 2002, 57, 1101.

17. Pavolovska, G.; Cundeva, K.; Stafilov, T.; Croat. Chem. Acta 2001, 74, 121.

18. Cundeva, K.; Pavolovska, G.; Stafilov, T.; J. Ser. Chem. Soc. 2001, 66, 709.

19. Lin, T.; Nriaju, J. O.; Anal. Chim. Acta 1999, 395, 301.

20. Luo, F. G.; Hou, X. D.; At. Spectrosc. 1994, 15, 216.

21. Ivanova, E.; Yan, X. P.; van Mol, W.; Adams, F.; Analyst 1997, 122,1 .
22. Xu, Z. R.; Xu, S. K.; Fang, Z. L.; At. Spectrosc. 2000, $21,17$.

23. Alexandratos, S. D.; Stine, C. L.; Sachlebem, R. A.; Mojer, B. A.; J. Polymer 2005, 46, 6347.

24. Jia, C.; Luo, Y.; Pawliszyn, J.; J. Microcol. Sep. 1998, $10,167$.

25. Abov-Mesalam, M. M.; EL-Nagar, I. M.; Abdel-Hai, M. S.; EL-Shahawi, M. S.; J. Radioanal. Nucl. Chem. 2003, 258, 619.

26. Gesser, H. D.; Ahmed, S.; J. Radioanal. Nucl. Chem. 1990, $140,395$.

27. Sooksamiti, P.; Geckeis, H.; Grudpan, K.; Analyst 1996, 121, 1413.

28. Bakircioglu, Y.; Segade, S. R.; Yourd, E. R.; Tyson, J. F.; Anal. Chim. Acta 2003, 485, 9.

29. Dimitrova, B.; Benkhedda, K.; Ivanova, E.; Adams, F.; Can. J. Anal. Sci. Spectrosc. 2004, 49, 346.

30. Yost, T. L.; Fagan, B. C.; Allain, L. R.; Barnes, C. E.; Dai, S.; Sepaniak, M. J.; Xue, Z.; Anal. Chem. 2000, 72, 5516.

31. Hiraide, M.; Sorouradin, M. H.; Kawaguchi, H.; Anal. Sci. 1994, $10,125$.

32. Manzoori, J. L.; Sorouradin, M. H.; Haji Shabani, A. M.; J. Anal. At. Spectrom. 1998, 13, 305.

33. Dadfarnia, S.; Haji Shabani, A. M.; Dehghan Shirie, H.; Bull. Korean Chem. Soc. 2002, 23, 545.

34. Dadfarnia, S.; Salmanzadeh, A. M.; Haji Shabani, A. M.; J. Anal. At. Spectrom. 2002, 17, 1434.

35. Haji Shabani, A. M.; Dadfarnia, S.; Dehghan, K.; Talanta 2003, 59, 719.

36. Dadfarnia, S.; Haji Shabani, A. M.; Tamaddon, F.; Rezaei, M.; Anal. Chim. Acta 2005, 539, 69.

37. Falomir, F.; Alegria, A.; Barbera, R.; Farre, R.; Lagarda, M. J.; Food Chem. 1999, 64, 111.

38. Schlemmer, G.; Welz, B.; Spectrochim. Acta, Part B 1986, 41, 1157.

39. Xiao-Quan, S.; Zhe-Ming, N.; Li, Z.; Talanta 1984, 31, 150.

40. Stafilov. T.; Cundeva, K.; Talanta 1998, 46, 1321.

41. Izatt, R.; Bradshaw, J.; Nielsen, S. A.; Lamb, J. D.; Christensen, J. J.; Chem. Rev. 1985, 85, 271.

Received: March 14, 2007 Web Release Date: November 9, 2007 